\title{
SARS-CoV-2 and Dentistry-Review
}

\author{
Clóvis Lamartine de Moraes Melo Neto ${ }^{1,} \quad$ Lisiane Cristina Bannwart ${ }^{1} \quad$ André Luiz de Melo Moreno ${ }^{2}$ \\ Marcelo Coelho Goiato ${ }^{1,3}$
}

1Department of Dental Materials and Prosthodontics, São Paulo

State University (UNESP), School of Dentistry, Araçatuba,

São Paulo, Brazil

${ }^{2}$ Brazilian Institute of Northern Education (IBEN), Manaus, Amazonas, Brazil

${ }^{3}$ Oral Oncology Center, São Paulo State University (UNESP),

School of Dentistry, Araçatuba, São Paulo, Brazil

\begin{abstract}
Address for correspondence Clóvis Lamartine de Moraes Melo Neto, DDS, MSc, PhD, Department of Dental Materials and Prosthodontics, São Paulo State University (UNESP), José Bonifácio, 1193, Araçatuba, São Paulo, Brazil - 16050-050 (e-mail: lamartineclovis@gmail.com).
\end{abstract}

\begin{abstract}
Keywords

- COVID19

- SARS-CoV-2

- dentist; dentistry

- professional-patient transmission

- Coronaviruses

- Coronavirus Infections

- Severe Acute

Respiratory Syndrome 2

SARS-CoV-2 (or 2019-nCoV) is the novel Coronavirus that affects humans. It originated in China at the end of 2019 due to the consumption of animals contaminated with this pathogen. SARS-CoV-2 causes the disease known as COVID-19 (coronavirus disease - 2019), and until May 21, 2020, approximately 213 countries and territories had been affected by SARS-CoV-2. The objective of this study was to review the origin and characteristics of this virus (SARS-CoV-2), symptoms and diagnosis of COVID-19, treatment of people with COVID-19, forms of transmission of the SARS-CoV-2, and precautions in dentistry. A literature search on PubMed/Medline was performed on the May 21, 2020, using the keywords (Mesh terms) "COVID-19" or "SARS-CoV-2" or "Coronavirus" associated with "dentistry" or "dental care" or "oral medicine." SARS-CoV-2 articles about the origin and characteristics of this virus (SARS-CoV-2), symptoms and diagnosis of COVID-19, treatment of people with COVID-19, forms of transmission of the SARS-CoV-2, and precautions in dentistry were included. The search was expanded according to necessity. Articles related to precautions in dentistry and SARS-CoV-1 or MERS-CoV were also selected, since precautions used in the dental clinic to avoid these viruses also apply to SARS-CoV-2. In addition, the references cited in the publications of articles included were also considered when appropriate. There was no limit in relation to the year of publication, and only articles written in English were included. In this study, suggestions for the safety of dental professionals were also included. Forty-seven articles and nine websites were included in this review.
\end{abstract}

\section{Introduction}

The novel Coronavirus known as SARS-CoV-2 (also called 2019-nCoV) is the seventh Coronavirus discovered in the world which affects human beings, causing the disease known as COVID-19 (coronavirus disease - 2019). ${ }^{1-4}$ To the extent that the number of COVID-19 cases increase, the world's health, economy and social stability have been disrupted. ${ }^{5}$ Until May 21,2020 , approximately 213 countries and territories had been affected by SARS-CoV-2. The United States of America (USA)
(1,604,109 cases), Russia (317,554 cases), Brazil (296,033 cases), Spain (280,117 cases), United Kingdom (250,908 cases), Italy (228,006 cases), France (181,575 cases), and Germany (178,864 cases) are on the top of the list of the most afflicted countries. ${ }^{6}$

In clinical practice, dental professionals are exposed to a large risk of infection by SARS-CoV-2, due to communication and contact with various patients every day. ${ }^{7.8}$ According to Ahmed et al, dental practitioners around the globe are in a state of anxiety and fear while working in their respective fields due to the impact of the COVID-19 pandemic on humanity. ${ }^{8}$ Thus, to
DOI https://doi.org/ 10.1055/s-0040-1716438 ISSN 1305-7456. (c) 2020. European Journal of Dentistry.

This is an open access article published by Thieme under the terms of the Creative Commons Attribution-NonDerivative-NonCommercial-License, permitting copying and reproduction so long as the original work is given appropriate credit. Contents may not be used for commercial purposes, or adapted, remixed, transformed or built upon. (https://creativecommons.org/licenses/by-nc-nd/4.0/) Thieme Medical and Scientific Publishers Pvt. Ltd., A-12, 2nd Floor, Sector 2, Noida-201301 UP, India 
help reduce anxiety and fear, dental professionals must follow the recommendations of regulatory authorities ${ }^{8}$ and scientific studies to protect themselves from SARS-CoV-2. In this way, dentists and other dental professionals can preserve their own health, the health of patients, and of the people around them in general. ${ }^{8}$ Therefore, the objective of this study was to review the origin and characteristics of this virus (SARS-CoV-2), symptoms and diagnosis of COVID-19, treatment of people with COVID19 , forms of transmission of the SARS-CoV-2, and precautions in dentistry.

\section{Methods}

A literature search on PubMed/Medline was performed on the May 21, 2020, using the keywords (Mesh terms) "COVID-19" or "SARS-CoV-2" or "Coronavirus" associated with "dentistry" or "dental care" or "oral medicine." SARS-CoV-2 articles about the origin and characteristics of this virus (SARS-CoV-2), symptoms and diagnosis of COVID-19, treatment of people with COVID-19, forms of transmission of the SARS-CoV-2, and precautions in dentistry were included. The search was expanded according to necessity. Articles related to precautions in dentistry and SARSCoV-1 or MERS-CoV were also selected, since precautions used in the dental clinic to avoid these viruses also apply to SARSCoV-2. In addition, the references cited in the publications of articles included were also considered when appropriate. There was no limit in relation to the year of publication, and only articles written in English were included. In this study, suggestions for the safety of dental professionals were also included. Fortyseven articles and nine websites were included in this review.

\section{Review}

The history of Coronaviruses that infect humans began in the decade of the 1960 s with the identification of $229 \mathrm{E}-\mathrm{CoV}$ and OC43-CoV. ${ }^{9}$ Subsequently, approximately 40 years later, SARSCoV-1 emerged in 2002, ${ }^{1-4,9}$ followed by two other Coronaviruses in 2004/2005, named NL63-CoV and HKU1-CoV. ${ }^{9}$ Some years later in 2012, MERS-CoV was reported, ${ }^{1-4,9}$ and SARS-CoV-2 emerged in 2019. ${ }^{1-4,7,10-19}$ Thus, to date, seven Coronaviruses have affected humans, of which four (NL63-CoV, 229E-CoV, OC43-CoV, and HKU1-CoV) cause symptoms of a common cold in general. ${ }^{2,3,10}$ According to Roussel et al, NL63-CoV, 229E-CoV, OC43-CoV, and HKU1-CoV cause 10 to $20 \%$ of all the respiratory infections in the world and are present on all continents. ${ }^{4}$

The other three are highly pathogenic ${ }^{1}$ and cause serious infectious diseases known as "severe acute respiratory syndrome", caused by SARS-CoV-1, "middle east respiratory syndrome", caused by MERS-CoV, and COVID-19, caused by SARS-CoV-2.1-4,7,10,11,13,19 According to $\mathrm{Xu}$ et al, these three viruses can cause respiratory, intestinal, hepatic, and neuronal diseases, and can lead to an acute respiratory distress syndrome (ARDS), multiple organ failure, and even death in severe cases. ${ }^{1}$

Coronaviruses vary from $50 \mathrm{~nm}$ to $150 \mathrm{~nm}$ in diameter, ${ }^{9}$ with projections on their surfaces similar to a crown when seen in an electronic microscope. ${ }^{3}$ Coronaviruses are nonsegmented, enveloped, positive-sense, single-stranded RNA viruses., .,3,9,11 $^{\text {The ori- }}$ gin of these viruses is zoonotic and belongs to the Coronaviridae family in the Nidovirales order, which are divided into four genera: alfa, $\beta$, delta, and gamma. ${ }^{7,11,20}$ The gamma and delta coronaviruses principally infect birds, and the alfa and $\beta$ coronaviruses principally infect the respiratory, gastrointestinal, and central nervous systems of humans and mammals., ${ }^{2,7} \mathrm{HCoV}-229 \mathrm{E}$ and HCoV-NL63 are classified as alfa, and HCoV-OC43, HCoV-HKU1, 2,20 SARS-CoV-1, MERS-CoV, and SARS-CoV-2 are $\beta$ coronaviruses.

\section{SARS-CoV-1}

SARS-CoV-1, also known as SARS-CoV, is a pathogen arising from bats, with palm civet cats being the intermediary host. 3,10,20 SARS-CoV-1 was reported in November of 2002 in the province of Guangdong, China. ${ }^{9,10,20,21}$ In February of 2003, an infected doctor from Guangdong traveled to Hong Kong, causing the worldwide dissemination of this virus. ${ }^{3,10}$ The disease soon spread to approximately 32 countries, from which 8447 cases and 774 deaths were reported. ${ }^{10}$ The spread of this virus was controlled in the beginning of July 2003, principally due to the measures of quarantine. Although there were some cases between 2003 and 2004, ${ }^{9}$ the spread of the virus was contained. ${ }^{9}$

The incubation period of this virus is from 2 to 7 days. ${ }^{12,22}$ The transmission of this virus can be through contact of contaminated hands or objects in the mucosa of the nose, mouth, and eyes, as well as inhalation of droplets ${ }^{23}$ and bioaerosols ${ }^{21}$ liberated during coughing, breathing, and speaking. ${ }^{21,23}$ The risk factors for patients with SARS-CoV-1 include advanced age and infection by other viruses or bacteria. ${ }^{24}$ The symptoms of patients with SARS-CoV-1 can be a persistent fever, headache, muscular pain, a decrease in the white blood cell blood count, ${ }^{1}$ and pneumonia. ${ }^{23}$ More severe problems include ARDS, failure of multiple organs, and even death. ${ }^{1}$ SARS-CoV-1 uses the angiotensin-converting enzyme 2 (ACE-2) receptor to enter human cells. ${ }^{1,2,20,24}$

\section{MERS-CoV}

This Coronavirus also arises from bats and was transmitted to human beings through camels (intermediary host).,10,20 In 2012, this disease initially occurred in Saudi Arabia and spread through other countries, including the USA, UK, France, and South Korea. ${ }^{1,4,10}$ This virus was reported in approximately 27 countries until February of 2020, with 2494 cases causing 858 deaths. ${ }^{25}$

The incubation period varies from 2 to 15 days. ${ }^{26}$ The means of transmission of this virus can be through bioaerosols and secretion droplets liberated through speech, respiration, and coughing, as well as contact with contaminated hands and objects on mucous membranes. ${ }^{27}$ The infection of MERS-CoV in patients can be characterized by fever, cough, shortness of breath, ${ }^{1}$ chills, sore throat, myalgia, arthralgia, vomiting, and diarrhea. ${ }^{26}$ Patients with serious cases of MERS-CoV can rapidly develop respiratory and renal insufficieny, ${ }^{1}$ in which the disease can lead to death ${ }^{1,26}$ Obese, immunocompromised, and diabetic patients, with cardiac disease and infected with other viruses or bacteria, have a greater chance of morbidity and mortality. ${ }^{24}$ MERS-CoV uses the dipeptidyl peptidase-4 receptor to enter human cells. ${ }^{1,20,24}$ 
According to Jamieson, no licensed vaccines exist for SARS-CoV-1 or MERS-CoV, although various strategies have been attempted in animal models. ${ }^{24}$ Also, there are no antiviral strategies for SARS-CoV-1 or MERS-CoV that are clearly effective. ${ }^{24}$ The principal antivirals used for SARS-CoV-1 and MERS-CoV were ribavirin, lopinavir, and ritonavir in a possible combination with interferon therapy. ${ }^{12,24}$

\section{SARS-CoV-2}

On December 31, 2019, 27 cases of a pneumonia of an unknown cause were identified in the city of Wuhan, China. ${ }^{1-3,5,7,10-19,25,28}$ Wuhan is a populous city with more than 11 million people. ${ }^{3,12,16}$ It was observed that these patients were connected, in some way, to a market in Wuhan that sold live animals such as fish, birds, bats, marmots, and snakes. ${ }^{5,12,16}$ On this same date, China notified the outbreak to the World Health Organization (WHO), and on January 1,2020 , that food market in Wuhan was closed. ${ }^{3}$ On January 10, 2020, the unknown pathogen was identified as a novel Coronavirus, which affects humans, and designated as "2019-nCoV" (2019-novel coronavirus) by WHO.,11 On January 30, 2020, WHO declared the new viral disease as a "public health emergency of international concern" 5,7,28 On February 11,2020, the disease was named "COVID-19" (coronavirus disease -2019) by the WHO, 7,25 and the virus was renamed "SARS-CoV-2" (severe acute respiratory syndrome coronavirus 2) by the International Committee on Taxonomy of Viruses. ${ }^{7}$ For this virus, it was verified that bats are the primary

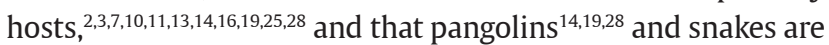
the intermediary hosts..$^{19,28}$

On March 5, 2020, 96,000 cases of COVID-19 with 3,330 deaths were reported in $\sim 97$ countries around the world. ${ }^{3}$ On April 12, 2020, 1,836,338 cases of COVID-19, with 113,255 deaths and 420,982 recuperations, were reported in $\sim 213$ countries and territories around the world. ${ }^{6}$ On May 21, 2020, 5,150,036 cases of COVID-19, with 332,074 deaths and $2,055,127$ recuperations, were reported in $\sim 213$ countries and territories around the world. ${ }^{6}$ Therefore, it is evident that the number of cases is increasing rapidly in the world.

In relation to the nucleotide sequence, SARS-CoV-2 presents approximately $79 \%$ similarity to SARS-CoV-1 $1^{2,3,7,16,19}$ and approximately 50\% similarity to MERS-CoV. ${ }^{7}$ SARS-CoV-2 possess high-transmissibility and infectiousness compared with SARS-CoV-1 and MERS-CoV 7,16,19 Mild cases of SARSCoV-2 exhibit symptoms such as fatigue, dry cough, vomiting, diarrhea, ${ }^{1,2}$ shortness of breath, ${ }^{2}$ sore throat, ${ }^{2,14}$ phlegm, headache, and hemoptysis. ${ }^{7}$ Serious cases involve pulmonary edema, pneumonia, organ failure, ${ }^{12}$ hypoxemia and/or respiratory difficulty, acute respiratory distress syndrome, septic shock, metabolic acidosis, and even death. ${ }^{1,2}$

All ages are susceptible to SARS-CoV-2., ${ }^{3,14}$ It is important to emphasize that healthcare professionals and hospitalized individuals who are close to patients infected by SARS-COV-2 are at high risk of being infected by this virus. ${ }^{5,7,12,14}$ According to Sabino-Silva et al, 29\% of the 138 patients hospitalized with pneumonia due to SARS-CoV-2 in Wuhan, China, were health professionals. ${ }^{13}$ It is also worth mentioning that advanced age and the existence of comorbidities (e.g., diabetes and hypertension) are associated with a worse prognosis. , $^{2,3,7,8,14,28}$ Smoking also has been reported as a probable factor associated with the negative progression of COVID-19. ${ }^{15}$

\section{Transmission of SARS-CoV-2}

SARS-CoV-2 can remain infectious (viable) on inanimate surfaces (e.g., plastic and stainless steel) at 21 to $23^{\circ} \mathrm{C}(40 \%$ relative humidity) for up to 3 days. ${ }^{29}$

The incubation period of SARS-CoV-2, which is the elapsed time between exposure of an individual to the virus and the manifestation of the first symptoms of the disease, varies from 1 to 14 days. ${ }^{2,3,5,7,8,14,19,28}$ Nevertheless, there are reports of an incubation period of 24 days. ${ }^{7,19,28}$ Another important factor is that SARS-CoV-2 can be contagious during the latency period (incubation); ;,12,14 therefore, this virus could be transmitted

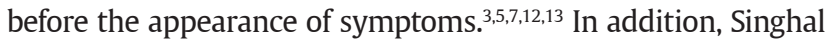
reported that patients can be infectious for as long as the symptoms last and even on clinical recovery. ${ }^{3}$ Despite these factors, Guo et al reported that SARS-CoV-2 could be less virulent than SARS-CoV-1 and MERS-CoV, with a current mortality rate of approximately 3.4\% (SARS-CoV-2), which is less than the mortality rate of SARS-CoV-1 ( 9,6\%) and MERS-CoV $(\sim 35 \%){ }^{2}$

Some factors related to the spread / transmission of a respiratory virus include temperature, humidity, and daily habits of a person (e.g., hygiene, places frequented, etc.). ${ }^{30}$ Moruyama et al speculated that the spread of SARS-CoV-2 among people would be faster in an environment with low humidity and low temperature, because these characteristics would contribute to the survival of this virus in the environment and facilitate its transmission. ${ }^{30}$ Moreover, it is worth highlighting that today, most people realize diverse interactions in closed locations (e.g., to work, to sleep, to travel, etc.), sharing breathable air, which facilitates viral transmission. ${ }^{30}$

The spread of SARS-CoV-2 also depends on the health system of each country. De Ceukelaire and Bodini report that in many countries around the world, public health systems have been gradually dismantled. ${ }^{31}$ In addition, another problem would be related to the privatization of health systems. ${ }^{31}$ According to De Ceukelaire and Bodini, privatization could affect the coordination capacity of large-scale preventive campaigns, limit the expansion of curative services, and generate incapacity to coordinate adequate collective responses. ${ }^{31}$ De Ceukelaire and Bodini also report that SARSCoV-2 is spreading rapidly across Europe and the USA in a manner which is making it possible to witness the vulnerability of more privatized healthcare systems. ${ }^{31}$

Respiratory viruses possess three means of transmission: 1 ) contaminated droplets with a $5 \mu \mathrm{m}$ or more diameter which travel directly to the facial mucosae of a person. ${ }^{5,32}$ The droplets are dispersed over short distances $(<1 \mathrm{~m})^{32} ; 2$ ) bioaerosols with less than $5 \mu \mathrm{m}$ of diameter which remain in the air for more time and can be transported over long distances $(>1 \mathrm{~m})^{5,32}$; 3) direct contact, for example, of a contaminated hand to the facial mucosae, or indirect, from a contaminated object to a mucosa. ${ }^{14,32}$ When sneezing, it is possible to generate a million droplets of up to $100 \mu \mathrm{m}$ in diameter, besides many thousands 
of larger particles are formed, in their majority, by the saliva. ${ }^{21,33}$ Coughing or speaking for 5 minutes can create approximately 3,000 droplet nuclei. ${ }^{33}$

The means of SARS-CoV-2 transmission is being studied. ${ }^{13}$ Nonetheless, the transmission of SARS-CoV-2 between humans was confirmed, $8,13,34,35$ and thus it is worth discussing the possibilities and means of contamination.

SARS-CoV-2 can be present in the respiratory tract. ${ }^{2,7}$ SARSCoV-2 was also identified in the blood ${ }^{2,13}$ and saliva. ${ }^{13,19,34,35}$ Therefore, coughing, sneezing and speech can generate droplets and bioaerosols contaminated with SARS-CoV-2, and thus, they can be means of transmission of this virus., ${ }^{2,3,734}$ SabianoSilva et al suggested three means by which SARS-CoV-2 could enter saliva: 1) SARS-CoV-2 in the inferior and superior respiratory tract could enter the oral cavity, together with secretion droplets frequently exchanged by the organs of these regions ${ }^{13}$; 2) SARS-CoV-2 present in the blood could access the mouth via crevicular fluid ${ }^{13}$; 3) due to an infection of the salivary glands (probably by being sources of this virus), thus the liberation of SARS-CoV-2 would occur in the saliva through the salivary ducts. ${ }^{13}$ It is worth highlighting that in dentistry, routine procedures could create droplets and aerosols $s^{5,7,13,14}$ with saliva, ${ }^{13,19,34,35}$ respiratory secretions, ${ }^{2,7}$ and blood ${ }^{2,13}$ that may be

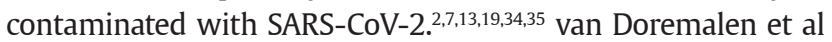
reported that SARS-CoV-2 remained viable in aerosols throughout their research ( 3 hours). ${ }^{29}$ Thus, cross-contamination can be facilitated with procedures of this nature, infecting patients and dental professionals.

SARS-CoV-2 can also be found in the gastrointestinal tract. ${ }^{19}$ In dentistry, various procedures can induce vomiting (e.g., molding and radiographic procedures), which can generate bioaerosols. Therefore, the vomit and bioaerosols generated during this process would be probable means of transmitting this virus.

Another form of transmission would be by direct contact. ${ }^{34}$ Feces, ${ }^{2,3}$ urine, tears, conjuctive ${ }^{19}$ and respiratory secretions, ${ }^{2}$ blood, ${ }^{2,13}$ and saliva ${ }^{13,19,34,35}$ can contain SARS-CoV-2, 2,3,13,19,34,35 and it can also be present on nonsanitized hands. Due to compliance, it is possible for one contaminated hand to contaminate another during a handshake. Thus, hands contaminated with SARS-CoV-2 can enter into contact with the oral, nasal, and ocular mucosae, promoting the entrance of this virus into the organism. ${ }^{2,3,7}$ Kwok et al evaluated the frequency of touches to the face in a sample of 26 students during two lectures of 2 hours each. ${ }^{36}$ It was observed that on average these students touched their faces 23 times per hour. ${ }^{36}$ Of all the facial touches performed by the students, $44 \%$ involved contact with a mucosa, while $56 \%$ of the touches involved nonmucosal areas. ${ }^{36}$ of the mucosal touches observed, 36\% involved the mouth, 31\% involved the nose, $27 \%$ involved the eyes, and $6 \%$ involved combinations of these regions. ${ }^{36}$ Therefore, the lack of hand hygiene can be a favorable means of SARS-CoV-2 transmission. The kiss on the mouth could also be a means of direct contact since the mouth can contain saliva, ${ }^{13,19,34,35}$ respiratory secretions, ${ }^{2,7}$ and blood ${ }^{2,13}$ contaminated with SARS-CoV-2, 2,7,13,19,34,35 for example.

Indirect contact $^{32}$ would be characterized, for example, if a dental instrument contaminated with SARS-CoV-2 would enter into contact with an oral mucosa, promoting the entrance of this virus in the organism. It is worth highlighting that the cellular receptor known as ACE-2 is highly expressed in the oral cavity, principally in epithelial cells of the tongue., 5 SARS-CoV-2 enters in the cells through this receptor (ACE-2). 2,3,7,19,28,35 Therefore, on contamination of the mouth with SARS-CoV-2 by direct or indirect means, it would be easy for this virus to infect a person. ACE-2 can also be present in the respiratory $\operatorname{tract}^{2,7,35}$ (e.g., nasal mucosa, lungs, and nasopharynx) $)^{37}$ salivary glands, ${ }^{7,35}$ kidneys, ${ }^{19}$ small intestine, ${ }^{2,37}$ colon, stomach, ${ }^{37}$ and other organs. According to Peng et al, the high affinity between this receptor and SARS-CoV-2 could suggest that people with a greater expression of ACE-2 could be more susceptible to SARS-CoV-2. ${ }^{7}$

There is no evidence of transplacental transmission, that is, between the fetus and the mother. ${ }^{3,19}$

\section{Diagnosis of Patients with SARS-CoV-2}

SARS-CoV-2 is diagnosed based on the epidemiological history (e.g., travel history) and the clinical syptoms, ${ }^{14,17}$ combined with a real-time reverse transcription polymerase chain reaction (RT-PCR) assay, ${ }^{8,17,35}$ high-throughput genome sequencing, or serological measurements of antiviral immunoglobulin $\mathrm{M}(\operatorname{IgM})$ and $\mathrm{G}(\operatorname{Ig} \mathrm{G})$ antibodies. ${ }^{17}$

\section{Treatment of Patients with SARS-CoV-2}

Some drugs such as remdesivir, chloroquine, and hydroxychloroquine are being studied for the treatment of people with COVID-19. 2,18,19,25 However, there are no specific drugs or vaccines related to SARS-CoV-2.8,12,19,31 The current treatments principally concentrate on respiratory support and control of the symptoms. ${ }^{2,3,19}$

\section{Precautions in the Dental Clinic}

According to Meng et al, standard daily protection measures in the dental clinic might not be effective or sufficient to avoid the transmission of SARS-CoV-2, principally when patients do not know that they are infected (asymptomatic) or opt to conceal their infection. ${ }^{14}$ Furthermore, health professionals infected with SARS-CoV-2 can be a source of cross-transmission. ${ }^{5}$ Therefore, the dentist that attends patients in this pandemic period of COVID-19 must have the following precautions:

\section{- Dental triage}

When a patient calls or seeks a dental office personally, requiring an appointment, it is important that the dentist asks questions to investigate the health situation of the patient. It is also important for the dental staff to call patients before the scheduled appointment to ask questions about their current health status. ${ }^{38}$ Questions that can be asked based on the studies of Peng et $\mathrm{al}^{7}$ and Samaranayake and Peiris $^{39}$ are as follows:

1. "Have you had a fever in the last 14 days (period of SARSCoV-2 incubation)?" 
2. "Have you had a respiratory problem such as a cough or shortness of breath in the last 14 days?"

3. "Have you, in the last 14 days, traveled internationally or visited an area where COVID-19 has been documented or suspected?"

4. "Have you been in contact with someone with SARS$\mathrm{CoV}-2$ in the last 14 days?"

5. "Have you been in contact with people with a fever and/or respiratory problems in the last 14 days?"

6. "Have you recently participated in a meeting, party, or event with the gathering of many unknown people?"

- If the patient recently arrived from a trip (less than 14 days), for example, the dental clinic could postpone the treatment until the incubation period ends..$^{39}$

- When the patient is scheduled in person or through a telephone call, advise the patient to use a facial cover when entering the dental clinic. ${ }^{38}$

- During the COVID-19 pandemic, it is recommended that dental clinics establish preverification triage to measure and register the temperature of each patient as a routine procedure. ${ }^{5,14,38}$ The symptoms of the respiratory tract should also be observed. ${ }^{5}$ If the patient is afebrile (temperature $<100.4^{\circ} \mathrm{F}$ ), and otherwise without symptoms consistent with COVID-19, then dental care may be provided. ${ }^{40}$

- Limit the number of people who accompany a patient to the appointment. If possible, the patient should make the visit alone..$^{38}$

- If the dentist receives a patient with characteristic symptoms (e.g., fever and fatigue) of COVID-19 in his/ her office, the dentist must converse with this patient using a surgical mask, avoiding physical contact. ${ }^{3}$ If these symptoms are not resulting from an acute dental infection, for example, ${ }^{5}$ the treatment should be postponed until the incubation period (14 days) ends, to reduce the risk of transmission.

- If the patient has been hospitalized due to COVID-19 for a short time (e.g., 1 week), and does not present more symptoms, attendance is not recommended. According to Samaranayake and Peiris, for SARS-CoV-1, dentists should postpone the treatment of convalescent patients for at least 1 month after discharge from the hospital. ${ }^{39}$ Based on this, this precaution is also important today due to SARS-CoV-2.

- If the dentist has mild symptoms similar to those caused by SARS-CoV-2, he/she should stop attending, advise the patients that were attended in the last 14 days about his/her condition, and recommend that they isolate themselves for 14 days.

- Periods of 24 days can also be investigated, since there are reports of a 24-day incubation for SARS-CoV-2., ${ }^{719,28}$

\section{- Waiting room}

- Remove reading materials and children's toys from the waiting room to avoid cross-contamination. ${ }^{26,38}$

- Post visual alerts (e.g., signs and posters) at the entrance of the waiting room to provide instructions about hand hygiene and respiratory hygiene. ${ }^{5,40}$ Information pamphlets can be produced and made available for the patients in the reception area, with recommendations from WHO about how to avoid the transmission of SARS-CoV-2 ${ }^{41}$ :

$\square$ When you cough or sneeze, cover your mouth and nose with an area of your arm when your elbow is bent. You can also use a cloth to cover your mouth and nose when you cough or sneeze. Next, it is necessary to discard the used cloth immediately.

$\square$ Stay home if you start to feel bad, even with mild symptoms such as a headache and light runny nose, until you recuperate. This way, you avoid contact with other people and medical installations. This will permit these installations to function more efficiently and will help to protect you and other people from contracting SARS-CoV-2 and other viruses.

$\square$ During isolation, maintain a healthy lifestyle.

$\square$ If you have a fever, cough, and respiratory difficulty, seek immediate medical attention.

$\square$ Wash your hands with soap and water regularly if they are visibly dirty. Use alcohol only if your hands are not visibly dirty. Wash the hands: after coughing and/or sneezing; before, during, and after preparing food; before eating; before using the bathroom; after petting or washing animals.

$\square$ Avoid spitting in public and avoid contact with people with a cough and/or fever.

$\square$ Avoid traveling if you have a cough and fever.

$\square$ Use disposable masks. Remember to cover your nose and mouth well. Avoid touching the mask when it is in position on the face. After removal of the mask, dispose of it immediately and wash hands.

$\square$ Avoid touching the eyes, nose, and mouth. The hands touch many surfaces and can catch SARS$\mathrm{CoV}-2$. Once contaminated, the hands can transfer the virus to the eyes, nose, and mouth.

- Place a hand sanitizer ${ }^{38}$ (e.g., $70 \%$ alcohol ${ }^{40,41}$ in the waiting room for patient use. ${ }^{38}$

- It is important that the dentist instructs his/her secretary and/or assistants as to the precautions, to avoid the transmission of SARS-CoV-2.

- Install physical barriers (e.g., glass or plastic windows) in the reception area to limit contact between screening personnel and potentially infectious patients. ${ }^{40}$

- In the waiting room, all patients should remain approximately $2 \mathrm{~m}$ away from each other. ${ }^{40}$

- It is important not to schedule patients at times close to each other, to avoid a gathering of people. ${ }^{38}$ In addition, to avoid crowding patients in the waiting room, it is possible to ask some of them to wait for dental care in their cars. ${ }^{38}$

\section{- Ventilation}

- The patients should be placed in an adequately ventilated waiting area. ${ }^{5}$ In rooms with natural ventilation, $60 \mathrm{~L} / \mathrm{s}$ per patient is adequate. ${ }^{5}$ 
- The patients can be treated in negative-pressure rooms with 12 changes of air per hour or at least $160 \mathrm{~L} / \mathrm{s}$ per patient in installations with natural ventilation. ${ }^{5}$

- To filter contaminated air in dental clinics, there are devices such as the high-volume evacuation (HVE) filter and the high-efficiency particulate air (HEPA) filter. ${ }^{5,42}$

- The filters in the suction apparatus must be cleaned every day. ${ }^{26}$

\section{- Personal protection equipment}

- The dentist must prohibit the circulation of employees without adequate protective equipment inside the dental care room during the treatment of a patient.

- Coats, caps, respirators, gloves, shoe covers, ${ }^{26}$ protective glasses and/or face protectors should be used to protect the skin and the mucosa from potentially infected blood and secretions. ${ }^{14}$ Observations:

$\square$ There are three types of nose and mouth protectors: cloth masks, surgical masks, and respirators. Cloth masks are not as protective as surgical masks or respirators. ${ }^{43}$ In addition, the protection furnished by surgical masks against particles $(0.04-1.3 \mu \mathrm{m})$ is 8 to 12 times less than N95 respirators. ${ }^{44}$ The National Institute for Occupational Safety and Hygiene of the USA classifies respirators as follows: N95, N99, N100, P100, P95, P99, P100, R95, R99, and R100. The letter $\mathrm{N}$ signifies that the respirators cannot be used in an environment with oil droplets; $R$ signifies that the respirators are slightly resistant to oil; and P signifies that the respirators are highly resistant to oil..$^{44,45}$ The P category can be used for protection against oily and nonoily aerosols. The numerical information demonstrates the filter efficiency of the respirator, that is, 95\%, 99\%, and 99.97\%.44,45 The European Standard (EN 149:2001) classifies the filtering facepiece (FFP) respirators as follows: FFP1, FFP2, and FFP3, with filter efficiencies of $80 \%, 94 \%$, and $99 \%{ }^{44}$ The FFP2 respirator is approximately equivalent to the N95 respirator. ${ }^{44}$ In the case of a pandemic and epidemic based on a respiratory virus, N95 or FFP2 respirator would be the best option for dentists in comparison to surgical masks.,14,26-28,38,39,42,44 However, as there could be a shortage of N95 and FFP2 respirators during a pandemic, ${ }^{44}$ it is possible that the dentist would need to acquire the N99, N100, P95, P99, P100, R95, R99, $\mathrm{R} 100$, or FFP3 respirators. It is worth mentioning that the respirator must be disposed and replaced by a new one after each dental treatment, since it is common for bioaerosols to contaminate the respirator. This corroborates the information provided by the National Institute for Occupational Safety and Hygiene, which reports that these respirators must be replaced whenever they are damaged, dirty, and/or causing a notable resistance to breathing. ${ }^{45}$ $\square$ Coats must not be used outside the environment of the dental office, since they can be carriers for the transmission of pathogens, ${ }^{46}$ such as SARS-CoV-2, potentially.

$\square$ Long coats with sleeves under the gloves should be used during appointments to avoid exposure of the forearm. ${ }^{42}$

\section{- Oral rinsing}

- Preoperative antimicrobial oral rinsing can reduce the number of microbes in the oral cavity. ${ }^{3,14}$ Although the effect of rinsing on SARS-CoV-2 present in the oral cavity is unknown, as a precaution, the use of $0.12 \%$ chlorhexidine, ${ }^{5,22,39,42} 1 \%$ hydrogen peroxide, ${ }^{7.8}$ or $0.2 \%$ povidone is recommend before a treatment. ${ }^{7}$

\section{- Bioaerosols}

- The dentist must minimize ${ }^{14}$ and exercise caution in the execution of procedures that create bioaerosols. ${ }^{13,41}$ Examples of how to avoid aerosols and splashes are as follows:

$\square$ Use a high-speed handpiece with antiretraction valves. ${ }^{7}$

$\square$ The use of a suction device $e^{1,38,42}$ and rubber dental dams ${ }^{5,14,22,38,39,42}$ can reduce the quantity of droplets and bioaerosols. 5,14,22,39,42

$\square$ A dental dam should be used in endodontic treatments. ${ }^{5}$ This is also valid for restoration treatments. ${ }^{42}$

$\square$ When possible, incorporate the dental dam in preparation of dental remnants to receive a prosthetic crown. 5.42

$\square$ The chemomechanical caries removal and the atraumatic restoration technique can be used to prevent or reduce the creation of bioaerosols and splashes. ${ }^{26,42}$

$\square$ If ultrasonic scrapers are extremely necessary, special devices to reduce aerosols can be used in combination with these devices. ${ }^{26}$

$\square$ Minimize the use of a triple syringe. ${ }^{42}$

$\square$ The use of topical spray to avoid the vomit reflex is not recommended, to avoid the risk of bioaerosol formations. ${ }^{42}$

$\square$ Avoid the prophylaxis procedure with rotary brushes. ${ }^{42}$

$\square$ Avoid the use of the spittoon.

\section{- Hygiene, disinfection, and sterilization}

- After the procedure, it is important to cautiously discard needles and other cutting materials immediately. ${ }^{26}$ If the material can be sterilized, it should also be taken to an appropriate location, washed, and sterilized. ${ }^{7,26}$ The discarding/removal of contaminated materials must be performed before the next appointment, to avoid cross-contamination. ${ }^{42}$

- Hygiene of the hands must be performed before and after procedures, ,13,14,26 and after touching the patient, the surroundings, and nondisinfected instruments. ${ }^{7}$ If the dentist is not attending, it is important to perform hand hygiene every 15 to 20 minutes. $^{3}$ 
- The hygiene can be performed with soap and water, and afterwards, it is recommended to apply 70 to $90 \%$ alcohol on the hands and rub them. ${ }^{5}$ The technique to wash hands with soap and water according to the Centers for Disease Control and Prevention ${ }^{47}$ is as follows:

1) Wet the hands with clean running water (hot or cold).

2) Close the faucet and apply soap.

3) Lather the hands, scrubbing them with the soap. Lather the back of the hands, between the fingers and under the nails.

4) Scrub the hands for at least 20 seconds. Do you need a timer? Sing the song "Happy Birthday" from beginning to end two times.

5) Rinse the hands well under clean running water.

6) Dry the hands with a clean towel or air.

- It is important to maintain the nails short and avoid the habit of biting the nails.

- Use disposable barriers on surfaces to protect them from clinical contact. ${ }^{42}$

- Restriction devices used to control the movement of pediatric patients (e.g., velcro fasteners) can be contaminated and must be disinfected adequately. ${ }^{26}$

- It is important to have time between each appointment and also to perform a complete cleaning of the office.

- In periapical radiographs without the use of a radiographic positioner, the patient should sanitize his/her hands before holding the radiographic film with the finger. If a positioner is used, sterilization must be performed, preferably after each use.

- Dentists and assistants should use white clothes and wash them frequently. White clothes facilitate the visual identification of possible contaminated areas. In addition, these clothes can obtain some contamination that is not visible, so ideally, dental professionals should only use them inside the dental office. ${ }^{22}$

- The dental apparatus and instruments can be contaminated with various pathogenic microorganism after use or by being exposed to a contaminated dental clinic environment. ${ }^{48}$ The contamination of surfaces in health environments is a potential source of viral transmission. ${ }^{48}$ No known studies exist about the effect of disinfectants on surfaces contaminated by SARS-CoV-2. However, for other coronaviruses that affect humans, 62 to $71 \%$ ethanol, $0.5 \%$ hydrogen peroxide, or $0.1 \%$ sodium hypochlorite can promote the inactivation of these pathogens on surfaces when exposed to the disinfectant for 1 minute. ${ }^{48}$ Therefore, provisionally, until new studies are performed with SARS-CoV-2, these disinfectants would be the best options. Examples of how they can be used are as follows:

$\square$ The disinfection of molds is essential to protect the people that deal with this personal dental material, since the mold enters in contact with saliva and eventually the blood. ${ }^{49}$ Wash molds before disinfecting to remove residues and maximize the effect of the disinfectant. ${ }^{49}$ After the washing of the alginate mold, $0.5 \%$ sodium hypochlorite can be sprayed on the mold and placed in a closed plastic bag for 10 minutes. ${ }^{50,51}$ After the washing of the addition silicone mold, it can be immersed in $1 \%$ or $5 \%$ sodium hypochlorite or 3\% hydrogen peroxide for 10 minutes. ${ }^{52}$ Based on the study by Kampf et al, the following disinfection techniques would be excellent options. ${ }^{48}$

$\square$ After arriving from the prosthetic laboratory, complete dentures can be washed with soap and water and immersed in $0.5 \%$ hypochlorite for 20 minutes. ${ }^{53}$ In the case of removable partial dentures, metal-ceramic crowns, and other prostheses with metallic structures, 62 to $71 \%$ ethanol could be suggested ${ }^{48}$ since hypochlorite can corrode the metal..$^{54}$

$\square$ In the dental office, the handles, chairs, tables, elevators, washrooms, and other surfaces should be frequently disinfected. ${ }^{7.8}$ Clean these surfaces thoroughly with detergent and water, and apply sodium hypochroite. ${ }^{48}$ The disinfection of device surfaces should be done after each patient visit. ${ }^{42}$

$\square$ Pressure and thermometer equipment must be disinfected with $70 \%$ alcohol after each use. ${ }^{5}$

$\square$ Orthodontic pliers should be sterilized..$^{55}$

$\square$ Before sending molds to the laboratory, it is fundamental to disinfect them, as well as inform the laboratory how the disinfection was performed. ${ }^{49}$ In addition, dental laboratories may not have knowledge about methods of disinfection ${ }^{49}$ so it is important for the dentist to disinfect the material received from the laboratory (e.g., dental crowns, complete dentures, etc.), before inserting them in the mouth of the patient.

$\square$ Disinfect triple syringes and the low- and high-speed handpieces (when they cannot be sterilized) with hypochlorite or ethanol. ${ }^{42}$

$\square$ Sterilize dental bits individually; in this way, each bit will be protected in its sterilization envelope from contamination by bioaerosols and/or contact. This method of individual sterilization should be used for other groups of material. It is important to highlight that pathogenic microorganisms (e.g., SARS-CoV-2) can be suspended in air and deposit themselves on sterile materials without protection.?

\section{- Infected patient in the dental office}

- If an individual has been diagnosed with SARS-CoV-2 and the dentist is aware of it, it is important to notify all people that were in the office together with the infected individual. It is recommended that the advised people remain in isolation at least 14 days and use masks. ${ }^{42}$ The dentist should also follow the same prerogative. ${ }^{42}$ This 
recommendation is fundamental for the contaminated individual to avoid close contact with their family and friends (kissing, hugging, close conversations, etc.). ${ }^{42}$

\section{- Dental procedures}

- Avoid the presence of unnecessary people in the dental treatment room. ${ }^{56}$ Avoid treating more than one patient in the same treatment room. Inside the treatment room there should be only one patient, one dentist, and one assistant.

- Use the 4-hands technique.,14

- For periodontal scrapping treatments, it is possible to perform the scrapping and coronoradicular smoothening with hand curettes, avoiding the use of ultrasonic devices. ${ }^{5,738}$

- For simple dental extractions, it is recommended that the suture thread be absorbable. ${ }^{14}$ This avoids the need for a new visit to the dentist to remove the sutures.

- During dental procedures, the dentist must avoid touching other objects in the office after contact with the saliva of the patient. ${ }^{5}$

- Laser and electrosurgery should be avoided since the smoke created may contain microorganisms. ${ }^{42}$

\section{- Cough and vomit}

- The procedures that will probably induce a cough (or vomit) should be avoided or performed with caution. ${ }^{14}$ Examples of how to avoid these reflexes are as follows:

$\square$ Select and adjust impression trays in the correct size to perform the modling. ${ }^{5.42}$

$\square$ Avoid placing the molding material in the mouth of the patient with a very fluid consistency, so that it does not run down the throat of the patient.

$\square$ Mold the patient in a $90^{\circ}$ position. According to Li et al, the patient should be in an adequate position, depending on the treatment. ${ }^{42}$

$\square$ A saliva suction should be performed with caution to avoid choking. ${ }^{5}$

$\square$ For patients who easily feel nausea during the molding, an oral mucosa anesthesia before the molding can help..$^{42}$ The sedation can control the vomit reflex in children. ${ }^{26}$

$\square$ CAD-CAM (computer-aided design and computer-aided manufacturing) technology can be helpful in some cases, to avoid a conventional molding. ${ }^{42}$

$\square$ It is important to be careful with patients who have blood in the buccal cavity due to lesions, since the blood could be swallowed/aspirated, causing a vomit reflex or cough. The excess of water in the oral cavity could also create the same effect. ${ }^{42}$

$\square$ Panoramic radiographs could be preferential in triage instead of periapical radiographs, to avoid a cough or vomitting. ${ }^{26,42}$

\section{- Dentistry schools}

- If a university prohibits clinical attendance and face-to-face classes, this must be respected to avoid crowding people.

- If the emergency department of a dental university is functioning, it is essential to follow safety precautions, such as those suggested by this review, to avoid contagion and transmission of SARS-CoV-2.

- Online studies, via cell phone or computer, can be used in this quarantine period. ${ }^{14}$

- Dentistry teachers should encourage their students to learn alone. ${ }^{14}$

- During this pandemic period, it is easy for students to be affected by fear of COVID-19. Therefore, dental schools must provide psychological services to students who need help. ${ }^{14}$

- Open communication between students, teachers, and staff can increase mutual trust and facilitate cooperation between them..$^{14}$

- Dentistry teachers must cancel courses to avoid crowding people.

\section{Conclusion}

For the dental professional (e.g., dentist), the best way to protect himself/herself from SARS-CoV-2 is with prevention.

\section{Conflict of Interest}

None declared.

\section{References}

1 Xu L, Liu J, Lu M, Yang D, Zheng X. Liver injury during highly pathogenic human coronavirus infections. Liver Int 2020;40(5):998-1004

2 Guo YR, Cao QD, Hong ZS, et al. The origin, transmission and clinical therapies on coronavirus disease 2019 (COVID-19) outbreak - an update on the status. Mil Med Res 2020;7(1):11

3 Singhal T. A review of Coronavirus disease-2019 (COVID-19) Indian J Pediatr 2020;87(4):281-286

4 Roussel Y, Giraud-Gatineau A, Jimeno MT, et al. SARS-CoV-2: fear versus data. Int J Antimicrob Agents 2020;55(5):105947

5 Ge ZY, Yang LM, Xia JJ, Fu XH, Zhang YZ. Possible aerosol transmission of COVID-19 and special precautions in dentistry. J Zhejiang Univ Sci B 2020;21(5):361-368

6 Worldometer. COVID-19 Coronavirus Pandemic. Available at: www.worldometers.info/coronavirus/\#countries. Accessed July 21, 2020

7 Peng X, Xu X, Li Y, Cheng L, Zhou X, Ren B. Transmission routes of 2019-nCoV and controls in dental practice. Int J Oral Sci 2020;12(1):9

8 Ahmed MA, Jouhar R, Ahmed N, et al. Fear and practice modifications among dentists to combat novel Coronavirus disease (COVID-19) outbreak. Int J Environ Res Public Health 2020;17(8):2821

9 Pyrc K, Berkhout B, van der Hoek L. Identification of new human coronaviruses. Expert Rev Anti Infect Ther 2007;5(2): 245-253 
10 Pan X, Ojcius DM, Gao T, Li Z, Pan C, Pan C. Lessons learned from the 2019-nCoV epidemic on prevention of future infectious diseases. Microbes Infect 2020;22(2):86-91

11 Yu F, Du L, Ojcius DM, Pan C, Jiang S. Measures for diagnosing and treating infections by a novel coronavirus responsible for a pneumonia outbreak originating in Wuhan, China. Microbes Infect 2020;22(2):74-79

12 Sohrabi C, Alsafi Z, O'Neill N, et al. World Health Organization declares global emergency: A review of the 2019 novel coronavirus (COVID-19) Int J Surg 2020;76:71-76

13 Sabino-Silva R, Jardim ACG, Siqueira WL. Coronavirus COVID-19 impacts to dentistry and potential salivary diagnosis. Clin Oral Investig 2020;24(4):1619-1621

14 Meng L, Hua F, Bian Z. Coronavirus disease 2019 (COVID-19): emerging and future challenges for dental and oral medicine. J Dent Res 2020;99(5):481-487

15 Vardavas CI, Nikitara K. COVID-19 and smoking: a systematic review of the evidence. Tob Induc Dis 2020;18:20

16 Hsu LY, Chia PY, Lim JF. The novel Coronavirus (SARS-CoV-2) epidemic. Ann Acad Med Singapore 2020;49(3):105-107

17 Dong X, Cao YY, Lu XX, et al. Eleven faces of coronavirus disease 2019. Allergy 2020;75(7):1699-1709

18 Gautret P, Lagier JC, Parola P, et al. Hydroxychloroquine and azithromycin as a treatment of COVID-19: results of an openlabel non-randomized clinical trial. Int J Antimicrob Agents 2020;56(1):105949 doi:10.1016/j.ijantimicag.2020.105949

19 Wang L, Wang Y, Ye D, Liu Q. Review of the 2019 novel coronavirus (SARS-CoV-2) based on current evidence. Int J Antimicrob Agents 2020;55(6):105948

20 Fehr AR, Perlman S. Coronaviruses: an overview of their replication and pathogenesis. Methods Mol Biol 2015;1282: $1-23$

21 Li Y, Huang X, Yu IT, Wong TW, Qian H. Role of air distribution in SARS transmission during the largest nosocomial outbreak in Hong Kong. Indoor Air 2005;15(2):83-95

22 Samaranayake LP; FDI Science Commission. Severe acute respiratory syndrome (SARS): an interim information paper for dental health care workers. Int Dent J 2003;53(3):117-118

23 Centers for Disease Control and Prevention (CDC). Frequently asked questions about SARS. Available at: www.cdc.gov/sars/ about/faq.html. Accessed July 21, 2020

24 Jamieson AM. Host resilience to emerging coronaviruses. Future Virol 2016;11(7):529-534

25 Raoult D, Zumla A, Locatelli F, Ippolito G, Kroemer G. Coronavirus infections: Epidemiological, clinical and immunological features and hypotheses. Cell Stress 2020;4(4): 66-75 doi:10.15698/cst2020.04.216

26 Al-Sehaibany FS. Middle East respiratory syndrome in children. Dental considerations. Saudi Med J 2017;38(4):339-343

27 Centers for Disease Control and Prevention (CDC). Interim infection prevention and control recommendations for hospitalized patients with Middle East Respiratory Syndrome Coronavirus (MERS-CoV). Available at: www.cdc.gov/coronavirus/mers/infection-prevention-control.html. Accessed July 21,2020

28 Yi Y, Lagniton PN, Ye S, Li E, Xu RH. COVID-19: what has been learned and to be learned about the novel coronavirus disease. Int J Biol Sci 2020;16(10):1753-1766

29 van Doremalen N, Bushmaker T, Morris DH, et al. Aerosol and surface stability of SARS-CoV-2 as compared with SARSCoV-1. N Engl J Med 2020;382(16):1564-1567

30 Moriyama M, Hugentobler WJ, Iwasaki A. Seasonality of respiratory viral infections. Annu Rev Virol 2020;7(1):83-101 doi:10.1146/annurev-virology-012420-022445

31 De Ceukelaire W, Bodini C. We need strong public health care to contain the global corona pandemic. Int J Health Serv 2020;50(3):276-277
32 Kutter JS, Spronken MI, Fraaij PL, Fouchier RA, Herfst S. Transmission routes of respiratory viruses among humans. Curr Opin Virol 2018;28:142-151

33 Xie X, Li Y, Chwang AT, Ho PL, Seto WH. How far droplets can move in indoor environments-revisiting the Wells evaporation-falling curve. Indoor Air 2007;17(3):211-225

34 Khurshid Z, Asiri FYI, Al Wadaani H. Human saliva: non-invasive fluid for detecting novel Coronavirus (2019-nCoV) Int J Environ Res Public Health 2020;17(7):2225

35 Hamid H, Khurshid Z, Adanir N, Zafar MS, Zohaib S. COVID19 pandemic and role of human saliva as a testing biofluid in point-of-care technology 2020. Eur J Dent 2020;14(suppl S1):S123-S129 doi:10.1055/s-0040-1713020

36 Kwok YL, Gralton J, McLaws ML. Face touching: a frequent habit that has implications for hand hygiene. Am J Infect Control 2015;43(2):112-114

37 Hamming I, Timens W, Bulthuis ML. Lely AT, Navis G, van Goor $\mathrm{H}$. Tissue distribution of ACE2 protein, the functional receptor for SARS coronavirus. A first step in understanding SARS pathogenesis. J Pathol 2004;203(2):631-637

38 American Dental Association (ADA). CDC Guidance for dental settings echoes ADA Guidance. Available at: www.ada.org/en/ publications/ada-news/2020-archive/june/cdc-guidance-fordental-settings-echoes-ada-guidance. Accessed July 21, 2020

39 Samaranayake LP, Peiris M. Severe acute respiratory syndrome and dentistry: a retrospective view. J Am Dent Assoc 2004;135(9):1292-1302

40 Centers for Disease Control and Prevention (CDC). Guidance for dental settings. Interim infection prevention and control guidance for dental settings during the COVID-19 response. Available at: www.cdc.gov/coronavirus/2019-ncov/hcp/dental-settings.html. Accessed July 21, 2020

41 World Health Organization (WHO). Coronavirus disease (COVID-19) advice for the public. Available at: www.who.int/ emergencies/diseases/novel-coronavirus-2019/advice-forpublic. Accessed July 21, 2020

42 Li RW, Leung KW, Sun FC, Samaranayake LP. Severe acute respiratory syndrome (SARS) and the GDP. Part II: implications for GDPs. Br Dent J 2004;197(3):130-134

43 Chughtai AA, Seale H, MacIntyre CR. Availability, consistency and evidence-base of policies and guidelines on the use of mask and respirator to protect hospital health care workers: a global analysis. BMC Res Notes 2013;6:216

44 Lee SA, Hwang DC, Li HY, Tsai CF, Chen CW, Chen JK. Particle size-selective assessment of protection of European standard FFP respirators and surgical masks against particles-tested with human subjects. J Healthc Eng 2016;2016:8572493

45 Centers for Disease Control and Prevention (CDC). National Institute for Occupational Safety and Hygiene (NIOSH) NIOSH Guide to the selection and use of particulate respirators certified under 42 CFR 84. Available at: www.cdc.gov/niosh/ docs/96-101/default.html. Accessed July 21, 2020

46 Priya H, Acharya S, Bhat M, Ballal M. Microbial contamination of the white coats of dental staff in the clinical setting. J Dent Res Dent Clin Dent Prospect 2009;3(4):136-140

47 Centers for Disease Control and Prevention (CDC). When and how to wash your hands. Available at: www.cdc.gov/handwashing/when-how-handwashing.html. Accessed July 21, 2020

48 Kampf G, Todt D, Pfaender S, Steinmann E. Persistence of coronaviruses on inanimate surfaces and their inactivation with biocidal agents. J Hosp Infect 2020;104(3):246-251

49 Al Mortadi N, Al-Khatib A, Alzoubi KH, Khabour OF. Disinfection of dental impressions: knowledge and practice among dental technicians. Clin Cosmet Investig Dent 2019;11:103-108

50 Badrian H, Ghasemi E, Khalighinejad N, Hosseini N. The effect of three different disinfection materials on alginate impression by spray method. ISRN Dent 2012;2012:695151 
51 Haralur SB, Al-Dowah OS, Gana NS, Al-Hytham A. Effect of alginate chemical disinfection on bacterial count over gypsum cast. J Adv Prosthodont 2012;4(2):84-88

52 Azevedo MJ, Correia I, Portela A, Sampaio-Maia B. A simple and effective method for addition silicone impression disinfection. J Adv Prosthodont 2019;11(3):155-161

53 Salles MM, Badaró MM, Arruda CNF, et al. Antimicrobial activity of complete denture cleanser solutions based on sodium hypochlorite and Ricinus communis - a randomized clinical study. J Appl Oral Sci 2015;23(6):637-642

54 Felipucci DN, Davi LR, Paranhos HF, Bezzon OL, Silva RF, Pagnano VO. Effect of different cleansers on the surface of removable partial denture. Braz Dent J 2011;22(5):392-397
55 Monteiro CGJ, Martins MM, Cury-Saramago AA, Teixeira HP. Biosafety conducts adopted by orthodontists. Dental Press J Orthod 2018;23(3):73-79

56 World Health Organization (WHO). Clinical management of severe acute respiratory infection when COVID-19 is suspected. Available at: www.who.int/publications-detail/ clinical-management-of-severe-acute-respiratory-infection-when-novel-coronavirus-(ncov)-infection-is-suspected. Accessed July 21, 2020 